J. Dairy Sci. 96:6529-6534

http://dx.doi.org/10.3168/jds.2013-6747

(C) American Dairy Science Association ${ }^{\circledR}, 2013$. Open access under CC BY-NC-ND license.

\title{
Technical note: A novel approach to the detection of estrus in dairy cows using ultra-wideband technology
}

\author{
E. M. Homer, ${ }^{*}$ Y. Gao,† X. Meng, † A. Dodson, $†$ R. Webb, ${ }^{*} \ddagger$ and P. C. Garnsworthy* ${ }^{*}$ \\ *University of Nottingham, School of Biosciences, Sutton Bonington Campus, Loughborough, LE12 5RD, United Kingdom \\ †Nottingham Geospatial Institute, Nottingham Geospatial Building, University of Nottingham Innovation Park, Triumph Road, Nottingham, \\ NG7 2TU, United Kingdom \\ ‡SRUC, Kings Buildings West Mains Road, Edinburgh, EH9 3JG, United Kingdom
}

\begin{abstract}
Detection of estrus is a key determinant of profitability of dairy herds, but estrus is increasingly difficult to observe in the modern dairy cow with shorter duration and less-intense estrus. Concurrent with the unfavorable correlation between milk yield and fertility, estrus-detection rates have declined to less than $50 \%$. We tested ultra-wideband (UWB) radio technology (Thales Research \& Technology Ltd., Reading, UK) for proof of concept that estrus could be detected in dairy cows (two 1 -wk-long trials; $\mathrm{n}=16$ cows, 8 in each test). The 3 -dimensional positions of 12 cows with synchronized estrous cycles and 4 pregnant control cows were monitored continuously using UWB mobile units operating within a network of 8 base units for a period of $7 \mathrm{~d}$. In the study, 10 cows exhibited estrus as confirmed by visual observation, activity monitoring, and milk progesterone concentrations. Automated software was developed for analysis of UWB data to detect cows in estrus and report the onset of estrus in real time. The UWB technology accurately detected 9 out of 10 cows in estrus. In addition, UWB technology accurately confirmed all 6 cows not in estrus. In conclusion, UWB technology can accurately detect estrus and hence we have demonstrated proof of concept for a novel technology that has significant potential to improve estrusdetection rates.
\end{abstract}

Key words: estrus, estrus detection, ultra-wideband technology, dairy cow

\section{Technical Note}

Poor estrus detection is a major contributor to reduced fertility in dairy cows. Traditionally, estrus detection was performed by visual observation for signs of mounting behavior, which is accurate, but larger herd

Received March 3, 2013

Accepted June 15, 2013.

${ }^{1}$ Corresponding author: phil.garnsworthy@nottingham.ac.uk sizes and less labor per cow reduce opportunities for visual observation, and detection is often below $50 \%$ (Van Eerdenburg et al., 2002; Roelofs et al., 2006). Automated technologies have been developed to obviate the need for visual observation. Pedometers and accelerometers are used to monitor increases in physical activity at estrus, with detection rates often 80 to $90 \%$ (Firk et al., 2002), some even achieving 100\% (At-Taras and Spahr, 2001). However, the error rate is variable and reported to range between 17 and 55\% (Firk et al., 2002). Mounting behavior can be monitored automatically by detection devices such as HeatWatch (CowChips LLC, Manalapan, NJ), which uses digital radio transmitters incorporating a pressure switch that are glued onto the tailhead and have a reported accuracy of $87.5 \%$ (Rorie et al., 2002). The most definitive indicator of estrus is a cow standing to be mounted. We hypothesized that this indicator might be detected by measuring the relative position of cows in 3 dimensions with advanced techniques, such as real-time ubiquitous positioning.

Ubiquitous positioning focuses on integrating global navigation satellite systems, including the global positioning system, which are capable of 3-dimensional positioning with other location technologies. The accuracy of these positioning systems ranges from a few millimeters to tens of meters, depending on the techniques and algorithms used, but they have poor accuracy and reliability indoors or in obstructed environments (Meng et al., 2007). Ultra-wideband (UWB) radio technology developed by Thales Research \& Technology Ltd. (Reading, UK), however, has proven accurate in harsh environments such as those subject to high multipath error and many obstructions (Ingram, 2006; Harmer et al., 2008) and can achieve positioning with centimeter accuracy in the horizontal and less than $30 \mathrm{~cm}$ in the vertical dimension (Ingram, 2006), which is the most difficult plane in which to achieve high accuracy. Therefore, UWB technology has potential for monitoring cows mounting and standing to be mounted using the specific interactions that occur at estrus and moni- 


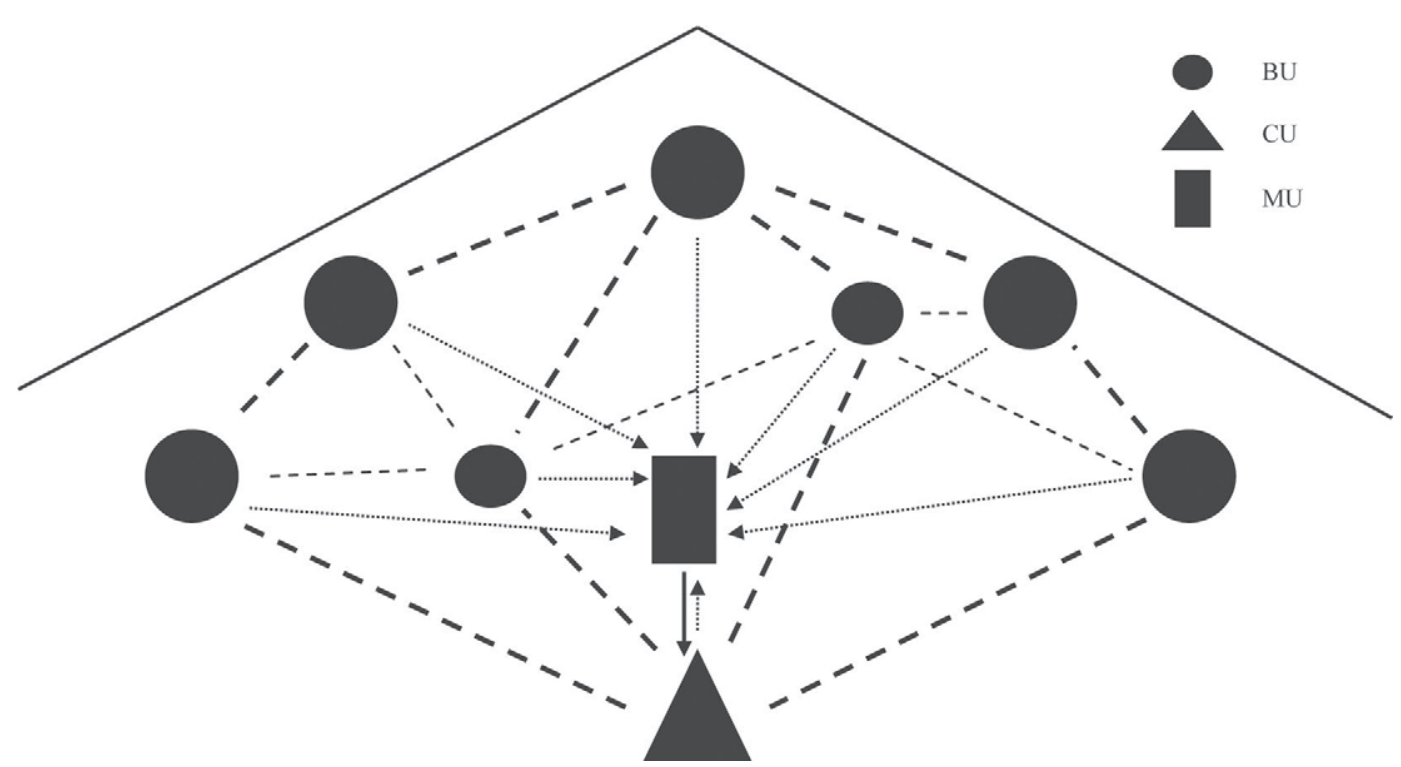

Figure 1. The 8 base units (BU) form a reference network between themselves (dashed line) in absolute positions that are known by the control unit (CU; also part of the BU network), connected to a computer. Each mobile unit (MU) within the BU network monitors broadcasts of BU positions (dotted arrows) and calculates its own position, which it reports to the CU (solid arrow), where position is stored in the computer.

toring changes in height. The objective of the current study was to investigate proof of concept that UWB technology could be used for accurate estrus detection.

Animal work was conducted under the authority of the UK Animal (Scientific Procedures) Act 1986, and approved by the University of Nottingham animal ethics committee. Animals used were 16 HolsteinFriesian dairy cows at Nottingham University Dairy Centre (Sutton Bonington, UK; average annual milk yield: 11,500 L/cow). Cows were housed in a freestall barn with 4 pens of approximately 40 cows. Cows were milked in automatic milking stations (Lely Astronaut A3; Lely UK Ltd., St. Neots, UK) between 2 and 5 times per day. All cows were fed the same silage-based diet, with concentrates fed at milking.

A reference network was established consisting of 8 base units (BU) in fixed locations (Figure 1). The BU network was set up with optimal geometry to cover the 2 pens used in this study and to provide accurate positioning for roaming mobile units (MU) attached to cows. Each BU broadcast its absolute position to all other units. This allowed each MU to calculate its own 3-dimensional position, which was transmitted back to a control unit (Figure 1) where data were stored. The MU were set to sample at a rate of $2 \mathrm{~Hz}$. Each cow was equipped with $1 \mathrm{MU}$ mounted in a backpack (Cassidy Covers Ltd., Dublin, Ireland) and connected to a battery pack (12 V 22 Amp h Tracer Lithium-Polymer Power Pack; Deben Group Industries Ltd., Suffolk, UK). Batteries were changed once per $24 \mathrm{~h}$ in the evening so as to minimize interference with the cows' nor- mal behavior. Cows were trained with backpacks and equipment before each trial. All cows displayed normal feeding, lying, and ruminating behavior, and mounting behavior was not inhibited.

The behavior of 8 cows was recorded in each of two 1-wk-long trials, recording position by UWB $24 \mathrm{~h}$ per day for $7 \mathrm{~d}$. In each trial, estrus of 6 cows (at least 40 DIM) was synchronized with controlled internal drug release (CIDR) devices (1.38 g of progesterone; InterAg, Hamilton, New Zealand), inserted into the vagina on $\mathrm{d}$ 0. Six days after CIDR insertion, $2.0 \mathrm{~mL}$ of Estrumate (cloprostenol sodium; synthetic analog of $\mathrm{PGF}_{2 \alpha}$ ) was injected intramuscularly, and on d 7, CIDR devices were removed.

At d 6, UWB recording commenced and continued until the morning of $\mathrm{d} 13$. During this period, cows came into estrus and were visually observed for estrous behavior from d 7 . Observations for signs of estrus were made for periods of $10 \mathrm{~min}$ at hourly intervals initially. More-frequent observations were made as cows began to show increased interest in herd mates, eventually resulting in continuous observation to record mounting and standing to be mounted. Four hours after the last episode of standing, estrus was deemed over.

Throughout the trial period from d 0 to 17 ( $5 \mathrm{~d}$ after UWB recording), 20-mL milk samples were collected via a Lely Shuttle Milk Sampler (Lely UK Ltd.) for progesterone analysis. Milk progesterone concentration was determined with a Ridgeway ELISA kit (Ridgeway Science Ltd., Gloucestershire, UK) following the manufacturer's protocol. Milk progesterone concentrations of 
$<1 \mathrm{ng} / \mathrm{mL}$ were used to confirm the accuracy of estrus detected both by UWB technology and visual observations.

The routine method of estrus detection on farm was activity monitoring. Activity data were recorded by a motion sensor (HR-Tags; SCR, Netanya, Israel), worn around the cow's neck and data were downloaded at each milking. Activity data were split into 12 readings daily of the number of activity units per 2-h interval. The onset of estrus was defined as the first of 3 consecutive periods of increased activity compared with baseline [4-d rolling average (forty-eight 2-h periods) activity]. The duration of estrus was determined as the period of sustained increased activity before returning to baseline. To confirm estrus detected by UWB, the percentage activity increase from baseline was calculated as the average of the three 2 -h periods with highest activity during the estrus period, divided by baseline activity.

The UWB data were analyzed alongside visual records of mounting and standing to be mounted events to confirm that these behaviors had been identified correctly by measured changes in height. Data were then analyzed by an automated Matlab script (Matlab R2009b; The MathWorks Inc., Natick, MA) to identify mounting and standing events by individual cows. Script 1 was developed to take into account the average dimensions of a Holstein-Friesian dairy cow and thus the relative position between 2 cows while one stood to be mounted by the other. Data were filtered to remove outlying values above and below the set height limits for a mount and to remove data of poor quality $(<80 \%$ signal strength). To identify individual mounts from UWB data, limits were applied to define a mount, taking into account the actual positions of $\mathrm{MU}$ on the 2 cows involved in mounting. Relative positions of cows were used to define mounting activity and to determine individual mounts by each cow.

After determining individual mounts, script 2 was applied to declare cows in estrus. Script 2 first identified an episode of mounting or standing to be mounted from script 1 and recorded time (t) and cow number (n). Script 2 then determined if any mounting or standing to be mounted occurred for cow $\mathrm{n}$ during the 3 -h period following time t. If such an event did occur, then the cow was confirmed in estrus and times of onset of mounting and onset of standing to be mounted were reported. The cow was thus declared in estrus. If script 1 reported isolated cases of individual mounts, not recurring within $3 \mathrm{~h}$, then the cow was not declared in estrus.

The results of this study demonstrate that the 3 -dimensional positions of cows can be recorded and analyzed to report specific mounting and standing be- haviors related to estrus. An example of the sequence of interaction between 2 cows is plotted in Figure 2 . These data show how the coordinates of the cows' positions in the $\mathrm{X}$ and $\mathrm{Y}$ (horizontal) axes and $\mathrm{Z}$ (vertical) axis changed in real-time as the cows interacted. The $\mathrm{Z}$ coordinate shows the height change as one cow mounts another cow that stands to be mounted. Figure 2 also illustrates behavior after mounting when height decreased as the cows moved apart.

Problems with indoor positioning lie in the integrity, reliability, and accuracy of position due to various obstructions (Meng et al., 2007, 2012). Ultra-wideband technology provides a high degree of horizontal accuracy $(1 \mathrm{~cm})$, whereas the vertical and, specifically, changes in height (such as those that occur during mounting) are the most difficult in which to achieve high accuracy (Harmer et al., 2008). It is important for the purpose of estrus detection that changes in height can be recorded accurately to detect mounting and standing behavior, which occur specifically at estrus. Ultra-wideband technology has a reported 30-cm accuracy in height (Ingram, 2006), but the results of the current study demonstrated an accuracy of $10 \mathrm{~cm}$ or less. Changes in height during mounting were approximately $40 \mathrm{~cm}$ (e.g., from 160 to $200 \mathrm{~cm}$; Figure 2), so UWB has sufficient accuracy in the height component for accurate estrus detection.

Of the 12 cows synchronized during the 2 trials, 10 cows displayed estrus. Results of automated script analysis of UWB data are in Table 1. One cow in estrus was eliminated from analysis as she was the only cow wearing a MU at the time, so her behavior could not be determined automatically because 2 units are required to determine relative positions of cows. Therefore, 9 out of 9 possible cows (Table 1) were detected in estrus automatically by UWB technology. Furthermore, 6 out of 6 possible cows were correctly identified as not in estrus.

Unlike other automatic systems, UWB monitors the most accurate sign of estrus, which is standing to be mounted (Orihuela, 2000). Ultra-wideband technology also monitors mounting behavior, which can signal the onset of estrus. Only $50 \%$ of cows are detected as standing to be mounted by periodic visual detection (Van Eerdenburg et al., 2002). Furthermore, it is reported that standing behavior occurs only for approximately $1 \%$ of the estrus period (Senger, 1994); hence, continuous monitoring is important. Mounting behavior has been reported to occur in $90 \%$ of periods of estrus (Roelofs et al., 2005), and is used as a method of estrus detection in some automated systems of detection, such as HeatWatch (Dransfield et al., 1998) and 4Sight (Fionn Technologies Ltd., Warrenpoint, UK; Esslemont, 2006). Most methods of detection, however, only focus on de- 


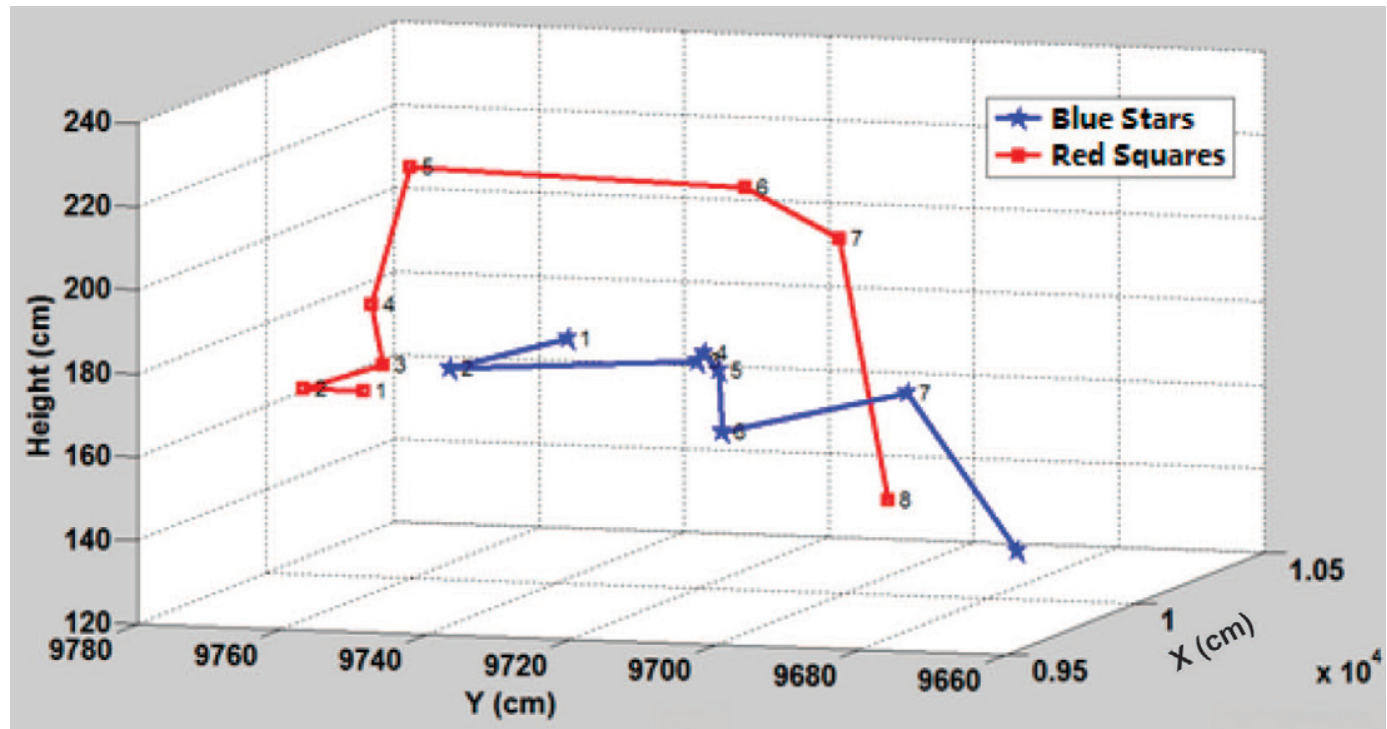

Figure 2. Example of mounting between 2 cows with 8 numbered points showing the sequence in time (1-s intervals) as cow 533 (blue line and stars) stood to be mounted by cow 543 (red line and squares). The 3-dimensional positions are shown: horizontal X and Y local coordinates and height $(\mathrm{Z})$ position in centimeters. Color version available in the online PDF.

tection of 1 sign of estrus. Monitoring both mounting and standing to be mounted by visual observations has been reported to increase heat detection rate from 12 to $30 \%$ when monitoring standing heat alone, to $61 \%$ when monitoring for mounting also (Van Eerdenburg et al., 1996; Roelofs et al., 2005). Therefore, UWB technology has the potential to be more accurate than other methods, by combining 2 behaviors for estrus detection.

The duration of estrus measured by UWB averaged $10.7 \mathrm{~h}$, ranging from 2.0 to $14.0 \mathrm{~h}$, which is comparable with other studies that reported an average duration of estrus of $7 \pm 5.4 \mathrm{~h}$ (Dransfield et al., 1998). Importantly, UWB is capable of detecting even the shortest duration of estrus (e.g., 2 h; Table 1) and estrus during unsociable hours; $44 \%$ of estrous behavior in this study occurred between 1800 and $0600 \mathrm{~h}$ when the herdsmen may not be present.

Estrus-detection accuracy of UWB compares favorably with accuracies reported for activity monitoring, which average 80 to $90 \%$ detection (Firk et al., 2002), with some studies reporting 100\% (At-Taras and Spahr, 2001). All cows detected in estrus by UWB were confirmed in estrus by increases in activity from baseline (Table 1). However, reports of activity monitoring are associated with high error rates (false positives), ranging from 17 to $55 \%$ (Firk et al., 2002). Error rate is influenced by the number of cows and estrus periods investigated, and can be attributed to different thresholds for detection and magnitude of activity increase, frequency of activity recording, and routine manage- ment tasks causing increases in activity. Importantly, UWB is more precise than activity monitoring because it detects standing to be mounted where only $2 \%$ error exists in identifying estrus (Kiddy, 1977). Furthermore, activity monitoring cannot always accurately predict the time of ovulation due to the retrospective nature of reports of increased activity and frequency of activity measurements. Activity increases have a weak relationship with standing estrus (Van Vliet and Van Eerdenburg, 1996), the sign of estrus most closely related to ovulation (Roelofs et al., 2005). Table 1 highlights the lack of precision when determining the onset of estrus by activity monitoring compared with UWB. Duration of sustained activity increase and duration of estrus determined by UWB and visual observation do not correlate well, probably because activity is recorded for 2 -h periods, which do not indicate a specific time of estrus.

Cows detected in estrus by UWB were also confirmed in estrus by a milk progesterone concentration of $<1$ $\mathrm{ng} / \mathrm{mL}$. Automated online monitoring of progesterone concentration achieved estrus-detection rates of 99.2 and $93.7 \%$ (Friggens et al., 2008), which are comparable to the accuracy of UWB. Progesterone monitoring is beneficial for determining errors in estrus detection (Nebel, 1988) and for determining potential silent heats (Harrison et al., 1990). Two cows that were synchronized had low milk progesterone concentrations $(<1 \mathrm{ng} / \mathrm{mL})$, yet did not show overt estrus and were also not detected in estrus by UWB. The decrease in 
progesterone concentration has a weak correlation with time of ovulation and optimal time for AI (Løvendahl and Friggens, 2008).

Although scripts were applied to the data posttrial, UWB can report estrus in real time, which allows the optimal time for AI to be determined and could improve conception rates. Reporting the onset of estrus increases the chance of conception because both mounting and standing are related to time of ovulation; 28.7 $\mathrm{h}$ after the onset of mounting and $26.4 \mathrm{~h}$ after standing heat (Roelofs et al., 2005).

One must be careful with the success rate found in this study due to the limited sample size. However, all cows identified in estrus by UWB were confirmed in estrus by other physiological and behavioral measurements. Therefore, the results show promise and proof of concept that UWB technology can be used for accurate estrus detection. Planned developments of a new prototype include miniaturization (to fit on a neck collar) and network expansion (more MU connected), which will enable larger-scale studies to be conducted.

In summary, UWB satisfies the criteria for an optimal method of estrus detection. Ultra-wideband technology provides a continuous method of detection, operating $24 \mathrm{~h}$ per day, accurately detecting cows in estrus, and reporting the optimal time for AI. These findings are of importance to the dairy industry, where other methods of estrus detection lack adequate efficiency and accuracy. In conclusion, UWB technology has the potential to improve estrus detection and AI success rates. This would result in improved dairy cow fertility and contribute to the sustainability of the dairy industry.

\section{ACKNOWLEDGMENTS}

This work was funded by the Engineering and Physical Sciences Research Council (EPSRC) and the University of Nottingham (Nottingham, UK). We thank Neil Saunders, Morag Hunter, Andrea Collishaw, Sarah Potterton, Roz Brennan, Cal Young, Reuben Newsome, Bobby Hyde, Natalie Heed, and Kirsty Hillier (all from University of Nottingham, Sutton Bonington, UK) for technical assistance with farm trials, Joseph Ryding (Nottingham Geospatial Institute, Nottingham, UK) and Thales Research \& Technology Ltd. (Reading, UK) for technical assistance with UWB work, and staff of the University of Nottingham Dairy Centre (Sutton Bonington, UK) for assistance with animal care.

\section{REFERENCES}

At-Taras, E. E., and S. L. Spahr. 2001. Detection and characterization of estrus in dairy cattle with an electronic heatmount detector and an electronic activity tag. J. Dairy Sci. 84:792-798. 
Dransfield, M. B. G., R. L. Nebel, R. E. Pearson, and L. D. Warnick. 1998. Timing of insemination for dairy cows identified in estrus by a radiotelemetric estrus detection system. J. Dairy Sci. $81: 1874-1882$.

Esslemont, R. J. 2006. Imagine a world with 100\% accurate heat detection-Is 4Sight the answer? Cattle Pract. 14:187-192.

Firk, R., E. Stamer, W. Junge, and J. Krieter. 2002. Automation of oestrus detection in dairy cows: A review. Livest. Prod. Sci. $75: 219-232$.

Friggens, N. C., M. Bjerring, C. Ridder, S. Højsgaard, and T. Larsen. 2008. Improved detection of reproductive status in dairy cows using milk progesterone measurements. Reprod. Domest. Anim. 43:113-121.

Harmer, D., M. Russell, E. Frazer, T. Bauge, S. Ingram, N. Schmidt, B. Kull, A. Yarovoy, A. Nezirovic, L. Xia, V. Dizdarevic, and K. Witrisal. 2008. EUROPCOM: Emergency Ultrawideband RadiO for Positioning and COMmunications. Vol. 3. Pages 85-88 in Proc. IEEE Intl. Conf. Ultra-Wideband (ICUWB) 2008, Hannover, Germany. Institute of Electrical and Electronics Engineers, New York, NY.

Harrison, R. O., S. P. Ford, J. W. Young, A. J. Conley, and A. E. Freeman. 1990. Increased milk production versus reproductive and energy status of high producing dairy cows. J. Dairy Sci. $73: 2749-2758$.

Ingram, S. 2006. UltraWideBand Indoor Positioning: Indoor positioning to match the best satellite navigation performance. Thales Research \& Technology (UK) Ltd. White Paper, Issue 2, NAV060601. Thales Research \& Technology Ltd. (Reading, UK)

Kiddy, C. A. 1977. Variation in physical activity as an indication of estrus in dairy cows. J. Dairy Sci. 60:235-243.

Løvendahl, P., and N. Friggens. 2008. Opportunities for online monitoring of health and performance in dairy cows. Pages 15-38 in Recent Advances in Animal Nutrition-2008. P. C. Garnsworthy and J. Wiseman, ed. Nottingham University Press, Nottingham, UK.
Meng, X., A. Dodson, T. Moore, and G. Roberts. 2007. Ubiquitous positioning; anyone, anything: Anytime, anywhere. GPS World 18:60-65.

Meng, X., Y. Gao, K.-H. Kwok, and H. Zhao. 2012. Assessment of UWB for ubiquitous positioning and navigation. Pages $1-6$ in Proc. of UPINLBS 2012, Helsinki, Finland. Institute of Electrical and Electronics Engineers, New York, NY.

Nebel, R. L. 1988. On-farm milk progesterone tests. J. Dairy Sci. $71: 1682-1690$

Orihuela, A. 2000. Some factors affecting the behavioral manifestation of estrus in cattle: A review. Appl. Anim. Behav. Sci. 70:1-16.

Roelofs, J. B., E. A. M. Graat, E. Mullaart, N. M. Soede, W. Voskamp-Harkema, and B. Kemp. 2006. Effects of insemination-ovulation interval on fertilization rates and embryo characteristics in dairy cattle. Theriogenology 66:2173-2181.

Roelofs, J. B., F. J. C. M. van Eerdenburg, N. M. Soede, and B. Kemp. 2005. Various behavioral signs of estrous and their relationship with time of ovulation in dairy cattle. Theriogenology 63:1366-1377

Rorie, R. W., T. R. Bilby, and T. D. Lester. 2002. Application of electronic estrus detection technologies to reproductive management of cattle. Theriogenology 57:137-148.

Senger, P. L. 1994. The estrus detection problem: New concepts, technologies, and possibilities. J. Dairy Sci. 77:2745-2753.

Van Eerdenburg, F. J. C. M., D. Karthaus, M. A. M. Taverne, I. Merics, and O. Szenci. 2002. The relationship between estrous behavioral score and time of ovulation in dairy cattle. J. Dairy Sci. 85:1150-1156.

Van Eerdenburg, F. J. C. M., H. S. H. Loeffler, and J. H. van Vliet. 1996. Detection of estrus in dairy cows: A new approach to and old problem. Vet. Q. 18:52-54.

Van Vliet, J. H., and F. J. C. M. Van Eerdenburg. 1996. Sexual activities and estrus detection in lactating Holstein cows. Appl. Anim. Behav. Sci. 50:57-69. 